\title{
Haematocrit and red blood cell transport in preterm infants: an observational study
}

\author{
P Pladys, A Beuchée, E Wodey, L Tison, P Bétrémieux
}

\begin{abstract}
Aims-To test whether cardiac output acts as a compensatory response to changes in haematocrit.

Methods-A cohort of 38 preterm infants (27-31 weeks' gestation) was studied with repeated Doppler measurements of left ventricular output during the 1 st month of life. Red blood cell transport was calculated when the duct was closed.

Results-Multiple regression analysis showed that left ventricular output correlated negatively with haematocrit when the duct was closed $(n=84)$ and when it was open $(n=59)$. The influence of an increase of $10 \%$ in haematocrit absolute value on mean (SD) left ventricular output was estimated at -55 (11) $\mathrm{ml} / \mathrm{kg} / \mathrm{min}$. Mean (SD) red blood cell transport was 132 (30) $\mathrm{ml} / \mathrm{kg} / \mathrm{min}$ with a mean (SD) intraindividual variability of $20 \%(8.8 \%)$. Red blood cell transport was increased more frequently by left ventricular output than by haematocrit. Haematocrit and left ventricular output but not red blood cell transport were dependent on postnatal age.

Conclusion-These results suggest that in preterm infants cardiac output adaptation is effective in attenuating the effects of red blood cell mass variations on systemic oxygen carrying capacity.
\end{abstract}

(Arch Dis Child Fetal Neonatal Ed 2000;82:F150-F155)

Keywords: prematurity; haematocrit; cardiac output; polycythaemia

The red blood cell mass of the newborn is greatly increased when compared with that of any other age, and varies widely during the first weeks after birth. These changes are particularly important in the sick preterm infant, who can be born with either a low or a high red blood cell mass, and who will be at risk of repeated blood sampling in conjunction with limited ability to regenerate red blood cell mass. If, initially, polycythaemia and hyperviscosity impede blood flow and compromise oxygen supply to the organs, subsequently, because the red blood cell is the major transporter of oxygen, the preterm infant with anaemia is at risk of inadequate oxygen delivery.

The haemodynamic consequences of a change in red blood cell mass have been studied using partial exchange transfusion in mature infants with polycythaemic hyperviscosity, in animal models, ${ }^{1-3}$ and in terms of the haemodynamic consequences of red blood cell transfusion. ${ }^{4-7}$ These studies have shown that red blood cell transfusion can lead to a decrease in cardiac output. This could be explained by an increase in vascular resistance, as a result of an increase in viscosity, or by the fact that the same amount of oxygen can be delivered to the tissues at a lower flow rate when the oxygen content of the blood is increased by the transfusion. The decrease in red blood cell mass induced by isovolaemic haemodilution in polycythaemia results in a decrease in blood viscosity and total vascular resistance, which in turn is associated with an increase in cardiac output. The effects of changes in red blood cell mass on the oxygen carrying capacity of the neonatal circulation are less clear. Oxygen carrying capacity has been estimated using oxygen delivery ${ }^{18}$ or using red blood cell transport (RCT), which is defined as the product of the venous haematocrit $(\mathrm{Ht})$ by left ventricular output (LVO): $\operatorname{RCT}(\mathrm{ml} / \mathrm{kg} / \mathrm{min})=\mathrm{Ht} \quad(\%) \times \mathrm{LVO} \quad(\mathrm{ml} / \mathrm{kg} /$ $\min ) / 100$. The oxygen carrying capacity has been shown to increase after transfusion for anaemia, ${ }^{47}$ or after therapeutic haemodilution for severe polycythaemia in human neonates when the haematocrit exceeds $70 \%{ }^{1}$ On the other hand, the effect of changes in red blood cell mass on red blood cell transport disappears in less severe polycythaemia, ${ }^{2}$ and oxygen delivery has been found to remain constant above a critical haemoglobin value, which varied with age and sex in a recent report on healthy adult volunteers subjected to isovolaemic haemodilution. ${ }^{9}$ The influence of red blood cell mass on oxygen carrying capacity has not been studied in preterm infants without polycythaemia.

Our study aimed to verify whether the influence of haematocrit on cardiac output observed in haemodilution studies was relevant in a cohort of preterm infants, and to evaluate the extent to which cardiac output adaptation induced by the changes in haematocrit could attenuate the changes in red blood cell transport.

\section{Methods}

PATIENTS

Preterm infants of gestational age greater than 27 and less than 32 weeks admitted to the neonatal intensive care unit of Rennes Teaching Hospital between May 1995 and May 1996 were eligible for our study. Thirty eight preterm infants were studied prospectively during this period. Infants with congenital heart disease or malformations were excluded. Our study protocol was approved by the institutional ethics committee of the Rennes 
Teaching Hospital and informed consent was obtained from the parents.

ECHOCARDIOGRAPHIC DATA COLLECTION

Echocardiographic evaluations of cardiac output and ductal patency were performed blinded to the venous haematocrit results. They were performed on days $1,2,4,8( \pm 1)$, and $21( \pm 7)$ and were correlated with venous haematocrit at the end of our study.

All neonates were examined while they were lying quietly in the supine position by the same investigators (PP or $\mathrm{AB}$ ). After a complete two dimensional echocardiographic examination to establish structural normality of the heart, haemodynamic function was assessed by serial $M$ mode, two dimensional, and pulsed wave Doppler echocardiography, with a Kontron ultrasonoscope. This machine had both 5.0 and $7.5 \mathrm{MHz}$ sector scan transducers. All the $M$ mode and pulsed wave Doppler measurements were performed with simultaneous visualisation of the transducer beam on the duplex two dimensional image. The size of the Doppler sample volume was set at an axial length of $2 \mathrm{~mm}$, with a wall filter setting of 150 or $400 \mathrm{~Hz}$.

The internal diameter of the ascending aorta was measured immediately distal to the aortic valves from a long axis view in $M$ mode at the end of systole, using the trailing edge to leading edge method..$^{10}$ This measurement was used to calculate the cross sectional area of the aorta $\left(\right.$ Sao $\left.=\pi \mathrm{d}^{2} / 4\right)$. The left ventricular outflow tract was imaged from a subcostal view, which visualises the full length of the ascending aorta. ${ }^{11}$ The transducer was manoeuvred to minimise the angle between the transducer beam and the presumed blood flow direction. The Doppler measurement was performed using pulsed wave Doppler. Because the angle between the estimated direction of blood flow and the Doppler beam was always $20^{\circ}$ or less, no angle correction of the Doppler signal was made. All Doppler recordings were performed with a Doppler sample volume in the centre of the vessel. Care was taken to place the sample volume where the internal diameter of the ascending aorta was measured (immediately distal to the aortic valves). The mean aortic flow velocity (Vao) was derived from the area under the external envelope of the curve of five consecutive beats at a steady state. The cardiac output, which is equal to systemic blood flow plus transductal blood flow when the duct is opened, was determined using the formula where Sao is the cross sectional area of the aorta, computed from $M$ mode measured diameter, and weight $(\mathrm{Wt})$ :

$\operatorname{LVO}(\mathrm{ml} / \mathrm{kg} / \mathrm{min})=\operatorname{Vao}(\mathrm{cm} / \mathrm{s}) \times$ Sao $\left(\mathrm{cm}^{2}\right) \times$ 60/Wt (kg).

In the parasternal short axis view, using pulsed wave Doppler, the ductus arteriosus was considered to be closed when the shunt flow was not detectable in the main pulmonary artery or in the duct. ${ }^{12} 13$

HAEMATOCRIT ANALYSIS

Haematocrit was measured from venous blood at the discretion of the attending physician.
Echocardiography was not performed if haematocrit analysis was not undertaken.

STATISTICAL ANALYSIS

The reproducibility of our Doppler and echocardiographic measurements has been reported previously. ${ }^{14}$ The coefficients of variation obtained were: Sao $(8.3 \%)$ and Vao $(4.8 \%)$. All statistical analyses were performed using Statistica (Statistica for Windows; Statsoft Inc, Tulsa, Oklahoma, USA). Data were expressed as mean (SD). The intraindividual variability was assessed by calculating the mean (SD) of the within individual coefficients of variation for test variables. The inter-individual variability was assessed by calculating the coefficient of variation of the individual means of the test variables. The Wilcoxon test or paired $t$ test was used to compare paired data as appropriate. The Fisher exact test or the $\chi^{2}$ test was used as appropriate.

Simple linear regression analysis was used first to assess the relations between the variables. Multiple regression analysis was used to describe the relation between haematocrit and left ventricular output and to calculate the relative influence of haematocrit on left ventricular output. The model studied was left ventricular output expressed as a function of haematocrit and postnatal age: $\mathrm{LVO}=\mathrm{A}+\mathrm{B}_{1} \cdot \mathrm{Ht}+\mathrm{B}_{2}$.age.

The absence of interaction between haematocrit and postnatal age on the left ventricular output prediction was verified in checking that zero was inside the $95 \%$ confidence interval of $\mathrm{B}_{3}$ by fitting the equation: $\mathrm{LVO}=\mathrm{A}+\mathrm{B}_{1}$. $\mathrm{Ht}+\mathrm{B}_{2}$.age $+\mathrm{B}_{3} \cdot$ Ht.age.

The standard analysis on residuals provided by the Statistica software was used to assess the validity of the model used for multiple regression analysis. The normal distribution of the residuals was assessed using a normal plot and the W Shapiro-Wilk test. The homogeneity of the variance of the residuals was verified using the graphs provided by Statistica. Because the number of measurements for each patient ranged from two to five, the median of the residuals was also calculated for each infant to check the homogeneity of the population with regard to the results of the multiple regression analysis. The normality of the distribution of these medians was then assessed using the W Shapiro-Wilk test.

In the graphs, the case by case relations were shown using the linear regression lines derived from individual infants when the data recorded were greater or equal to two.

During the analysis of the results, we found that expressing left ventricular output in $\mathrm{ml} / \mathrm{kg} /$ min was not totally appropriate for the newborns that we studied. Indeed, the analysis of the residuals of this correction showed a persistent significant correlation between the corrected left ventricular output and the weight. This persistent correlation was verified when pooled data were analysed (fig 1A), as well as when repeated measures were reduced to a single summary measure considering the individual as the basic unit. ${ }^{15}$ The summary measures used were the within individual 

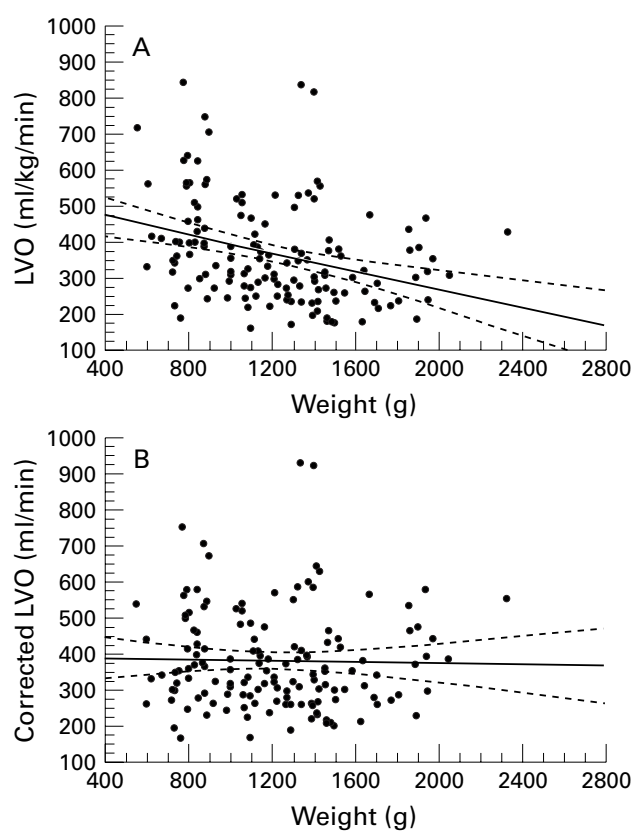

Figure 1 (A) The expression of left ventricular output (LVO) in $\mathrm{ml} / \mathrm{kg} / \mathrm{min}$ was found not to be appropriate for the 38 newborns studied $(n=143)$ because a relation between left ventricular output and weight persisted after correction $(r=-0.32 ; p<0.0001)$. (B) The corrected left ventricular output at $1 \mathrm{~kg}\left(\mathrm{LVO} \mathrm{O}_{\mathrm{u}}\right)$ calculated from the results of the simple regression analysis between left ventricular output and weight.

medians of the variable studied. Therefore, we have corrected left ventricular output at $1 \mathrm{~kg}$ $\left(\mathrm{LVO}_{1 \mathrm{~kg}}\right)$ using the results of the simple regression analysis between left ventricular output expressed in $\mathrm{ml} / \mathrm{min}$ and weight (Wt) expressed in g: $\mathrm{LVO}=153.61+0.23 \mathrm{Wt}$ $(r=0.47 ; \mathrm{p}<0.00001)$.

We verified that the parameters used in this function were not significantly different from those obtained in calculating the mean of the within individual regressions, and not significantly different from those obtained in calculating the regression when repeated measures were reduced to a single summary measure
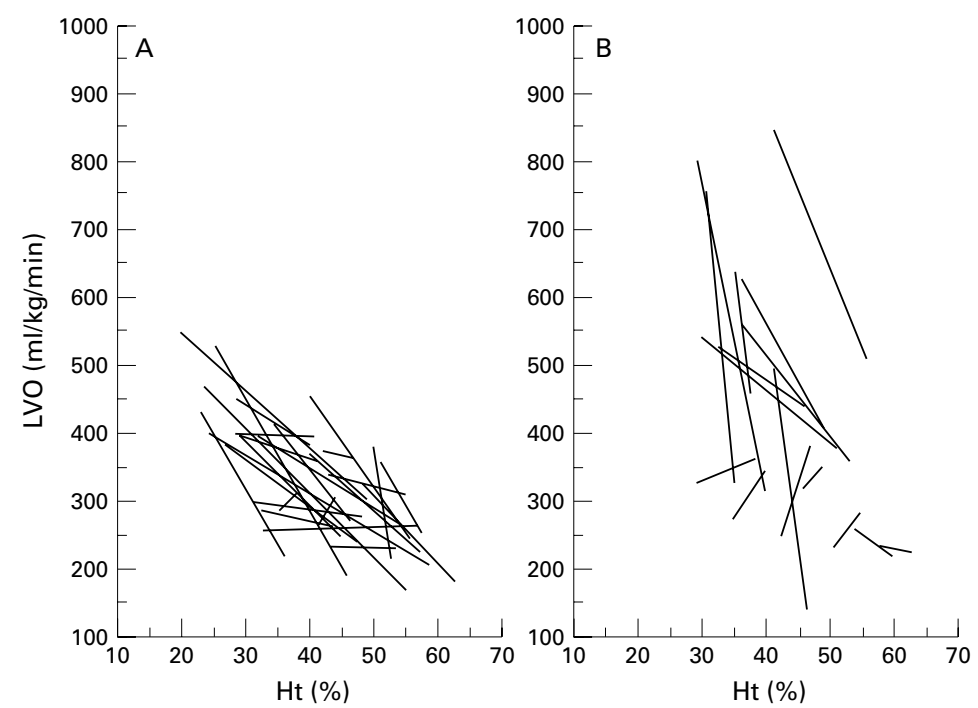

Figure 2 Correlation between left ventricular output (LVO) and haematocrit when (A) the duct was closed and (B) when it was open. Case by case relations are presented using the linear regression lines derived from individual infants when the data recorded were greater or equal to two. considering the individual as the basic unit (data not shown). This method permitted a better correction of the left ventricular output (fig 1B), which was used to verify the validity of all the results obtained with left ventricle output expressed in a conventional way. $\mathrm{LVO}_{1 \mathrm{~kg}}$ was expressed in $\mathrm{ml} / \mathrm{min}$ and was used in the calculation of $\mathrm{RCT}_{1 \mathrm{~kg}}$.

\section{Results}

Thirty eight infants with a mean (SD) gestational age of 29.3 (1.5) weeks and a mean (SD) birthweight of 1220 (370) g were studied. Echocardiographic measurements and haematocrit were recorded together on 143 occasions (median, 4 times/newborn; range, $2-5)$. The 47 missing data points arose as a result of death $(n=7)$, absence of the echocardiographers $(n=12)$, or missing haematocrit measurement $(n=28)$ at the time planned. The proportion of missing data points was not significantly influenced by postnatal age (eight on day 1,10 on day 2,10 on day 4, eight on day 8 , and 11 on day 21 ).

INFLUENCE OF THE HAEMATOCRIT ON LEFT VENTRICULAR OUTPUT

When the arterial duct was closed $(n=84)$

The results were obtained on mean (SD) day 9.4 (8.6); mean (SD) left ventricular output was 333 (99) $\mathrm{ml} / \mathrm{kg} / \mathrm{min}$ and mean (SD) haematocrit was $41.8 \%$ (10.2\%). Using simple regression analysis, we found that left ventricular output correlated negatively with haematocrit $(r=-0.68)$ and positively with postnatal age $(r=0.57)$. Multiple regression analysis confirmed the negative relation between left ventricular output and haematocrit (table 1). The validity of the model used, as well as the normal distribution of the population with regard to the results of multiple regression analysis, were verified. The influence of haematocrit on left ventricular output calculated from multiple regression analysis revealed that an increase of $10 \%$ in haematocrit absolute value would result in a mean (SD) change in left ventricular output of -55 (11) $\mathrm{ml} / \mathrm{kg} / \mathrm{min}$. Figure 2 shows the correlations between left ventricular output and haematocrit. Case by case analysis of this relation showed that left ventricular output decreased with the increase in haematocrit in 22 of 25 newborn infants $(\mathrm{p}<0.01)$.

When the duct was open $(n=59)$

The results were obtained on mean (SD) day 3.2 (3.1); mean (SD) left ventricular output was 421 (175) $\mathrm{ml} / \mathrm{kg} / \mathrm{min}$ and mean (SD) haematocrit was $42.8 \%(8.7 \%)$. Using simple regression analysis we found that left ventricular output correlated negatively with haematocrit $(r=-0.51)$ and positively with postnatal age $(r=0.60)$. Multiple regression analysis confirmed that the negative relation between left ventricular output and haematocrit persisted when the duct was open (table 1). The validity of the model used, as well as the normal distribution of the population with regard to the results of multiple analysis, were verified. The influence of haematocrit on left ventricular 
Table 1 Results of multiple regression analyses of left ventricular output (LVO) as a function of postnatal age and haematocrit

\begin{tabular}{|c|c|c|c|c|}
\hline & $\begin{array}{l}\text { Global and partial } \\
\text { coefficient of correlation }\end{array}$ & $B$ & $\begin{array}{l}\text { Standard } \\
\text { error of } B\end{array}$ & $p$ Value \\
\hline \multicolumn{5}{|c|}{ Closed duct $(n=84) A=545(57) \mathrm{ml} / \mathrm{min}$} \\
\hline LVO estimate & $r=0.69$ & & $72 \mathrm{ml} / \mathrm{kg} / \mathrm{min}$ & $\mathrm{p}<0.00001$ \\
\hline $\mathrm{X}_{1}=$ haematocrit $(\%)$ & $r=-0.48$ & -5.48 & 1.1 & $\mathrm{p}<0.00001$ \\
\hline $\mathrm{X}_{2}=$ postnatal age (days) & $r=0.15$ & 1.86 & 1.3 & NS \\
\hline \multicolumn{5}{|c|}{ Open duct $(n=59) A=579$ (112) $\mathrm{ml} / \mathrm{min}$} \\
\hline LVO estimate & $r=0.64$ & & $137 \mathrm{ml} / \mathrm{kg} / \mathrm{min}$ & $\mathrm{p}<0.00001$ \\
\hline $\mathrm{X}_{1}=$ haematocrit $(\%)$ & $r=-0.27$ & -5.5 & 2.4 & $\mathrm{p}<0.05$ \\
\hline $\mathrm{X}_{2}=$ postnatal age (days) & $r=0.46$ & 25.4 & 6.6 & $\mathrm{p}<0.001$ \\
\hline
\end{tabular}

output calculated from multiple regression analysis revealed that an increase of $10 \%$ in haematocrit absolute value would result in a mean (SD) change in left ventricular output of $-55(24) \mathrm{ml} / \mathrm{min}$, which is not significantly different from the effect of haematocrit calculated when the duct was closed. Figure 2 shows the correlations between left ventricular output and haematocrit. Case by case analysis of this relation showed that left ventricular output
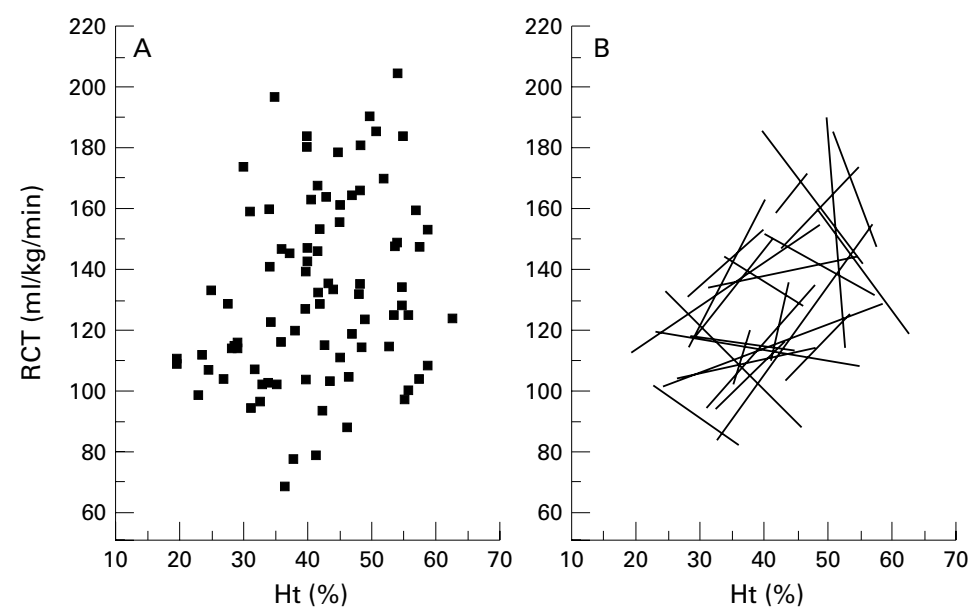

Figure 3 Correlation between red blood cell transport (RCT) and haematocrit when the duct was closed. (A) Pooled data $(n=84)$. Mean (SD) red blood cell transport was 132 (30) $\mathrm{ml} / \mathrm{kg} / \mathrm{min}$ and mean (SD) haematocrit was $41.8 \%$ (10.2\%). (B) Case by case relations using the linear regression lines derived from individual infants when the data recorded were greater or equal to two.
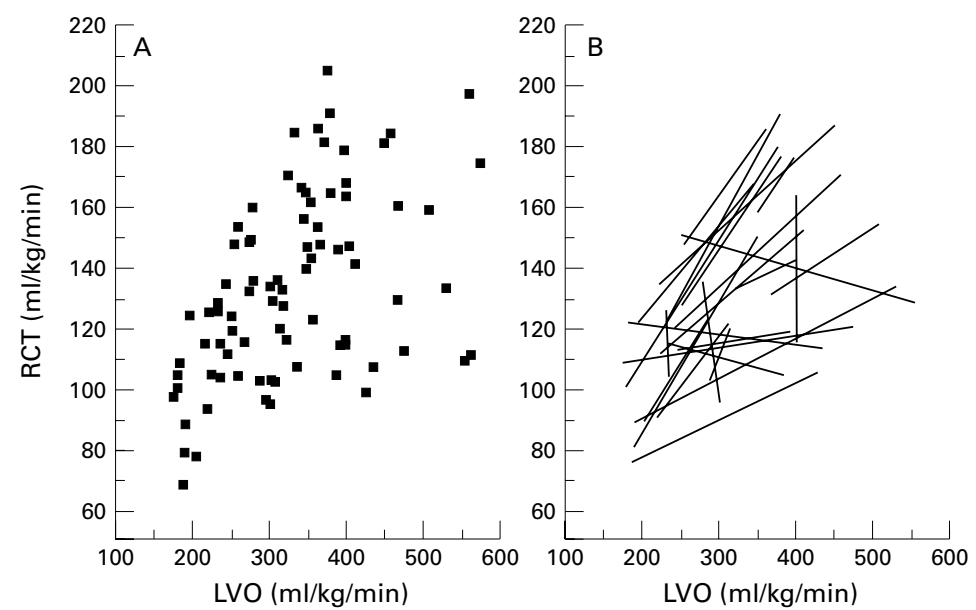

Figure 4 Correlation between red blood cell transport (RCT) and left ventricular output (LVO) when the duct was closed. $(A)$ Pooled data $(n=84)$. Mean (SD) left ventricular output was 333 (99) $\mathrm{ml} / \mathrm{kg} / \mathrm{min}$ and mean (SD) red blood cell transport was 132

(30) $\mathrm{ml} / \mathrm{kg} / \mathrm{min}$. (B) Case by case relations using the linear regression lines derived from individual infants when the data recorded were greater or equal to two. decreased with the increase in haematocrit in 11 of 16 newborn infants.

INFLUENCE OF HAEMATOCRIT AND LEFT

VENTRICULAR OUTPUT ON RED BLOOD CELL

TRANSPORT

Because red blood cell transport does not represent the oxygen carrying capacity of the systemic circulation when the duct is open, it was only analysed in the absence of a patent ductus arteriosus. The mean (SD) red blood cell transport was $132(30) \mathrm{ml} / \mathrm{kg} / \mathrm{min}$. The intraindividual variability did not differ significantly between red blood cell transport and left ventricular output (red blood cell transport: mean, $20 \%$; SD, $8.8 \%$; left ventricular output: mean, $24.9 \%$; SD, $15.2 \%$ ). The mean interindividual variability was $17.4 \%$ for red blood cell transport and $24.8 \%$ for left ventricular output. Using simple linear regression analysis we found that left ventricular output and haematocrit but not red blood cell transport were influenced by postnatal age $(r=0.56$ for left ventricular output and $r=-0.72$ for haematocrit). Case by case analysis confirmed the practical importance of left ventricular output in determining red blood cell transport (figs 3 and 4). Indeed, red blood cell transport increased more frequently with the increase in left ventricular output than with the increase in haematocrit $(76 \% \quad v 60 \%$ of the cases, respectively; $\mathrm{p}<0.05)$.

EXPRESSING THE RESULTS USING THE CORRECTED LEFT VENTRICULAR OUTPUT

The results of the simple and multiple regression analyses confirmed the negative correlations between haematocrit and $\mathrm{LVO}_{1 \mathrm{~kg}}$ (obtained from the simple regression analysis between left ventricular output expressed in $\mathrm{ml} / \mathrm{min}$ and weight) when the duct was closed as well as when it was open.

However, with this correction of left ventricular output the influence of haematocrit on $\mathrm{LVO}_{1 \mathrm{~kg}}$ calculated from multiple regression analysis was significantly increased when the duct was open $(p<0.0001)$ : an increase of $10 \%$ in haematocrit absolute value resulted in a mean (SD) change in $\mathrm{LVO}_{1 \mathrm{~kg}}$ of $-53(23) \mathrm{ml} /$ min when the duct was open and $-33(10) \mathrm{ml} /$ min when the duct was closed.

The results of the analysis of the influence of haematocrit and left ventricular output on red blood cell transport obtained with the conventional expression of left ventricular output were verified with the use of $\mathrm{LVO}_{1 \mathrm{~kg}}$, except for the mean (SD) intra-individual variability of $\mathrm{RCT}_{1 \mathrm{~kg}}$, which was $19.3 \% \quad(9.4 \%)$ lower $(\mathrm{p}<0.05)$ than the intra-individual variability of $\mathrm{LVO}_{1 \mathrm{~kg}}$ (mean, 26.6\%; SD, 16\%). The mean (SD) $\mathrm{RCT}_{1 \mathrm{~kg}}$ was 139 (31) $\mathrm{ml} / \mathrm{min}$.

\section{Discussion}

The negative correlation between haematocrit and cardiac output and the fact that red blood cell transport appeared to be highly dependent on cardiac output demonstrate the physiological importance of cardiac output evaluation in the estimation of the oxygen carrying capacity of the preterm infant. The observations that, 
unlike haematocrit and left ventricular output, red blood cell transport is not dependent on postnatal age, and that the intra-individual variability is lower for $\mathrm{RCT}_{1 \mathrm{~kg}}$ than for $\mathrm{LVO}_{1 \mathrm{~kg}}$ suggest that cardiac output adaptation is effective in attenuating the effects of red cell mass variations on red blood cell transport and systemic oxygen carrying capacity in preterm infants. This compensatory response might be mediated by the changes in haemodynamics induced by alterations in red cell mass as well as by concomitant alterations in plasma volume.

The negative correlation between cardiac output and haematocrit is consistent with the haemodynamic consequences reported after partial exchange transfusion in newborns with polycythaemic hyperviscosity and in animal models. ${ }^{1-3}{ }^{16}$ In these studies, the decrease in red cell mass resulted in a decrease in blood viscosity and total vascular resistance, which was associated with an increase in cardiac output induced by an increase in both heart rate and stroke volume. The reduction in haematocrit resulted in an increase in cardiac output: $63 \mathrm{ml} / \mathrm{kg} / \mathrm{min}$ for a reduction of $17 \%$ in haematocrit in the study of Swetnam and colleagues $^{1}$ and $58 \mathrm{ml} / \mathrm{kg} / \mathrm{min}$ for a reduction of $12 \%$ in the study of Mandelbaum et al. ${ }^{2}$ These variations seen in mature newborn infants were similar to the predicted changes calculated in our preterm infants, where a change of $10 \%$ in haematocrit resulted in a mean (SD) inverse modification in left ventricular output of 55 (11) $\mathrm{ml} / \mathrm{kg} / \mathrm{min}$. The amplitude of these changes emphasises the importance of the haematocrit in the interpretation of cardiac output in neonatal haemodynamic studies. We think that in sick preterm infants, measurements of haematocrit and red blood cell transport should be considered, together with the evaluation of the four determinants of cardiac function (preload, afterload, heart rate, and contractility) when an improvement in oxygen delivery is required.

Our measure of red blood cell transport was quite similar to the mean (SD) value of 159 (11) $\mathrm{ml} / \mathrm{kg} / \mathrm{min}$ reported previously in normal term infants. ${ }^{2}$ The evolution of red blood cell transport has been analysed in short term studies after red cell transfusion and after partial exchange transfusion. Red blood cell transport has been shown to increase by about $15 \%$ when packed cell volume is increased after red blood cell transfusion in preterm infants with anaemia. ${ }^{4}$ In this case, the increase in red blood cell transport might be the result of both increases in packed cell volume and volaemia. Using normovolaemic haemodilution in newborn infants with polycythaemia, Mandelbaum et al found that a decrease in packed cell volume of $12 \%$ resulted in an increase in cardiac output, with no significant change in red blood cell transport. ${ }^{2}$ This result supports our observation that cardiac output alterations attenuate the effect of red blood cell mass variations on red blood cell transport. This phenomenon might explain, at least in part, the tolerance to anaemia seen in many newborn infants, and the observation that the red blood

\section{Key messages}

- Red cell transport is an estimation of oxygen carrying capacity

- The effects of red blood cell mass variations on oxygen carrying capacity depend on the compensatory response provided by cardiac output adaptation

cell mass estimation did not predict which infants would benefit from transfusion. ${ }^{17} \mathrm{We}$ found that low red blood cell transport can arise as a result of low cardiac output as well as of low haematocrit (figs 3 and 4). This shows that both low red blood cell mass and lack of cardiac output adaptation can be limiting factors in red blood cell transport and oxygen delivery. We did not note any significant decrease in red blood cell transport at high haematocrit but we did not study the critical haematocrit values (haematocrit $>65 \%$ ), at which the risk of complications is known to rise. ${ }^{18}$ Similarly, we did not note any significant discrepancy in the relation between red blood cell transport and haematocrit, which could argue for a critical lower limit for red blood cell mass.

These results indicate that the measurement of red blood cell transport would be of value when assessing the need for red blood cell transfusion. Indeed, it appears to be more informative than the simple measurement of red blood cell mass (haematocrit, blood haemoglobin concentration, or red blood cell volume) for evaluating the oxygen transport capacity. For example, it is plausible that some red blood cell transfusion would be avoided in cases of haemodilution when a low haematocrit is associated with normal or high red blood cell transport. If the conditions and the amount of reduction in red blood cell transport that result in tissue hypoxia or in deleterious clinical effects could be defined, low red blood cell transport might become a good marker of the need for red blood cell transfusion. The main limitation to the clinical use of red blood cell transport might be the evaluation and the expression of cardiac output. Our results suggest that expressing the results as $\mathrm{ml} / \mathrm{kg} / \mathrm{min}$ is not necessarily the best adjustment for weight, and it is known that the measurement of cardiac output with Doppler techniques depends on the methodology used for measuring aortic diameter. Nevertheless, it has been shown to compare favourably with measures taken from invasive methods of assessing cardiac output in both human infants and newborn piglets. ${ }^{19} 20$

When the duct is open, the ability of the circulation to transport oxygen to the peripheral organs is difficult to evaluate because cardiac output does not represent systemic flow but is equal to the sum of systemic and transductal flow. In this situation, red blood cell transport is impossible to analyse without knowledge of the amount of transductal flow. Nevertheless, it is important to consider the important effect of haematocrit changes on cardiac output seen in 
some cases. Indeed, our results suggest that a decrease in haematocrit might sometimes result in an important increase in cardiac output and consequently in left to right shunting through the duct. This risk could be increased by the specific effect of haematocrit changes on pulmonary circulation. Indeed, it has been shown that the isovolaemic decrease in haematocrit results in an increase in the resistance gradient between the two circulations in both infants with ventricular septal defect and newborn lambs with patent ductus arteriosus. ${ }^{321}$ It is not possible to confirm this result from our study, but our observation that the calculated changes in $\mathrm{LVO}_{1 \mathrm{~kg}}$ induced by haematocrit were more important when the duct was open than when it was closed could be explained by such a phenomenon. Therefore, we think that this plausible specific effect, as well as the important influence of haematocrit on cardiac output, argue for maintaining relatively high haematocrit values (45-65\%) to limit important left to right shunting through the duct.

The authors thank Dr N Modi for her assistance in the preparation of this manuscript.

1 Swetnam SM, Yabek SM, Alverson DC. Hemodynamic consequences of neonatal polycythemia. $f$ Pediat 1987;110:443-7;

2 Mandelbaum VH, Guajardo CD, Nelle M, Linderkamp O. Effects of polycythaemia and haemodilution on circulation in neonates. Arch Dis Child Fetal Neonatal Ed 1994;71:F53-4.

3 Fouron JC, Hebert F. The circulatory effects of hematocrit variations in normovolemic newborn lambs. 7 Pediatr 1973;82:995-1003

4 Nelle M, Hocker C, Zilow EP, Linderkamp O. Effects of red cell transfusion on cardiac output and blood flow velocities in cerebral and gastrointestinal arteries in premature infants. Arch Dis Child Fetal Neonatal Ed 1994;71:F45-8.

5 Hudson I, Cooke A, Holland B, et al. Red cell volume and cardiac output in anaemic preterm infants. Arch Dis Child 1990;65:672-5.
6 Bifano EM, Smith F, Borer J. Relationship between determinant of oxygen delivery and respiratory abnormalideterminant of oxygen delivery and respiratory abnormalities in preterm

7 Yu CW, Sung RY, Fok TF, Wong EM. Effects of blood transfusion on left ventricular output in premature babies. $\mathcal{F}$ Paediatr Child Health 1998;34:444-6.

8 Holzman IR, Tabata B, Edelstone DI. Blood flow and oxygen delivery to the organs of the neonatal lamb as a function of haematocrit. Pediatr Res 1986;20:1274-9.

9 Weiskopf RB, Viele MK, Feiner J, et al. Human cardiovascular and metabolic response to acute, severe isovolemic cular and metabolic response to acut
anemia. $\mathcal{F} A M A$ 1998;279:217-21.

10 Hudson I, Houston A, Aitchison T, Holland B, Turner T. Reproducibility of measurements of cardiac output in newborn infants by Doppler ultrasound. Arch Dis Child 1990;65:15-19.

11 Nashashibi M, Chantepie A, Saliba E, Cheliakine C, Gold F, Laugier J. Measurement of cardiac output by Doppler echocardiography in neonates and infants. Pediatrie 1990;45:831-7.

12 Mellander M, Sabel KG, Mellgren G. Single Doppler detection of left to right shunt through the ductus arteriodetection of left to right shunt through the ductus
sus. Acta Paediatr Scand Suppl 1986;329:98-102.

13 Su BH, Watanabe T, Shimizu M, Yanagisawa Y. Echocardiographic assessment of patent ductus arteriosus shunt flow pattern in premature infants. Arch Dis Child Fetal Neonatal Ed 1997;77:F36-40.

14 Pladys P, Wodey E, Bétrémieux P, Beuchée A, Ecoffey C. Effects of volume expansion on cardiac output in the preterm infant. Acta Paediatr 1997;86:1241-5.

15 Matthews JNS, Altman DG, Campbell MJ, Royston P. Analysis of serial measurements in medical research. $B M \mathcal{F}$ 1990;300:230-5.

16 Teyssier G, Fouron JC, Sonesson SE, Bonnin P, Skoll A. Circulatory changes induced by isovolaemic increase in red cell mass in fetal lambs. Arch Dis Child Fetal Neonatal Ed 1998;79:F180-4

7 Alverson DC. The physiologic impact of anemia in the neonate. Clin Perinatol 1995;22:609-25.

18 Werner EJ. Neonatal polycythemia and hyperviscosity. Clin Perinatol 1995;22:693-711.

19 Mellander M, Sabel KG, Caidhal K, Solymar L, Eriksson B. Doppler determination of cardiac output in infants and children: comparison with simultaneous thermodilution. Pediatr Cardiol 1987;8:241-6.

20 Welch E, Duara S, Suguihara C, Bandstra E, Bancalari E. Validation of cardiac output measurements with noninvasive Doppler echocardiography by thermodilution and fick methods in newborn piglets. Biol Neonate 1994;66:13745.

21 Lister G, Hellenbranc WE, Kleinman CS, Talner NS. Physiologic effect of increasing hemoglobin concentration in left to right shunting in infants with ventricular septum defect. N Engl f Med 1982;306:502-6. 